\title{
Tantas verdades: os discursos científicos na construção social do ambiente
}

So many truths: scientific discourse in the social construction of the environment

\section{Beaucoup de vérités: les discours scientifique dans la construction sociale de l'environnement}

Tantas verdades: los discursos científicos en la construcción social del ambiente

\author{
Raiza Campregher* \\ Rodrigo Constante Martins*
}

Recebido em 18/06/2016; revisado e aprovado em 12/07/2016; aceito em 12/09/2016

DOI: http:/ / dx.doi.org/10.20435/1984-042X-2016-v.17-n.4(14)

\begin{abstract}
Resumo: A Represa do Broa, no interior do estado de São Paulo, é um pequeno reservatório para produção de energia hidrelétrica, utilizado também para recreação e turismo, e como laboratório a céu aberto para pesquisas na área de limnologia e engenharia hidráulica. $\mathrm{O}$ artigo em tela tem como objetivo compreender a produção de discursos científicos sobre a represa, bem como os efeitos específicos de poder desses discursos junto a outras esferas sociais, como a imprensa local. Palavras-chave: sociedade e meio ambiente; conflitos socioambientais; discurso científico.

Abstract: The Broa Dam, in São Paulo state, is a small reservoir for hydroelectric power production, also used for touristic and recreational purposes, and as an outdoor laboratory for research in limnology and hydraulic Engineering. This paper aims to comprehend the production of scientific discourses about the Broa Dam, as well as the specific effects of power from this discourses on other social spheres, as the local press.
\end{abstract}

Key words: society and environment; socio-environmental conflicts; scientific discourse.

Résumé: Le Barrage du Broa, dans l'état de São Paulo, est un petit réservoir de l'eau pour la production d'énergie hydroélectrique, également utilisé pour les activités de loisirs et le tourisme, et comment laboratoire à ciel ouvert pour les activités de recherche dans le domaine de la limnologie et de l'ingénierie hydraulique. Cet article vise à comprendre la production du discours scientifique sur le réservoir, ainsi que les effets de ce discours sur les autres sphères sociales, particulièrement la presse locale.

Mots-clés: la société et l'environnement; les conflits environnementaux ; le discours scientifique.

Resumen: La Presa del Broa, en el estado de Sao Paulo, es un pequeño embalse para producción de energía hidroeléctrica, también utilizado para recreación y turismo, y aún como un laboratorio al aire libre para pesquisas en limnología y ingeniaría hidráulica. El artículo tiene el objetivo de comprender la producción de discursos científicos sobre la presa, bien como los efectos específicos de poder de estos discursos junto a otras esferas sociales, como la prensa local.

Palabras clave: sociedad y medio ambiente; conflictos socio-ambientales; discursos científicos.

\section{INTRODUÇÃO}

A literatura da temática socioambiental é marcada pela divisão epistemológica entre trabalhos numa perspectiva realista e outros mais voltados ao enquadramento do construcionismo social (ALMEIDA; PREMEBIDA, 2014). Essa segunda vertente elabora a questão mais a partir da ação dos agentes sociais que argumentam sobre a natureza e menos a partir de critérios físicos fixos e associais (HANNIGAN, 2009). Nessa perspectiva, portanto, a realidade ambiental depende tanto dos fenômenos físico-químico-biológicos, quanto dos fenômenos sociais e discursivos relativos ao ambiente. Dessa forma, a própria emergência da moderna questão ambiental pode ser compreendida como uma construção social disputada a partir da produção de discursos. Ainda nesse enquadramento, a produção de

\footnotetext{
* Universidade Federal de São Carlos, São Carlos, São Paulo, Brasil.
} 
conhecimento científico sobre o meio ambiente ganha grande importância para análise sociológica: ela liga a interpretação de fenômenos físicos aos fenômenos sociais, produzindo discursos específicos sobre a natureza. E é sobre esse aspecto que este artigo se interessa: a construção social do meio ambiente por meio de discursos científicos.

Este texto apresenta um estudo de caso realizado na Represa do Broa, um local privilegiado para a análise sociológica de certas problemáticas ambientais, particularmente aquelas ligadas ao conhecimento científico do mundo natural. A represa, também conhecida apenas como Broa, é o reservatório da Usina Hidrelétrica Carlos Botelho, localizado entre os municípios de Brotas e Itirapina no interior do estado de São Paulo. Além da produção de energia hidrelétrica, o reservatório serve a outras duas funções: o Broa é um espaço de lazer e recreação para a população da região central do estado; e é utilizado pela USP e UFSCar (localizadas na cidade de São Carlos, SP) como um laboratório a céu aberto para pesquisas na área de limnologia e engenharia hidráulica. Por razão desse arranjo social, existe uma extensa produção científica sobre as condições ambientais da represa, a qual, por vezes, extrapola as fronteiras do campo científico e influencia disputas discursivas entre cientistas, turistas, jornalistas, autoridades dos governos municipais etc. sobre a realidade socioambiental do Broa.

$\mathrm{O}$ artigo em tela tem como objetivo compreender a produção de discursos científicos sobre a Represa do Broa, bem como os efeitos específicos de poder desses discursos junto a outras esferas sociais em particular a imprensa local. As metodologias utilizadas no estudo foram a pesquisa bibliográfica, a pesquisa documental de trabalhos científicos sobre a Represa do Broa e de notícias jornalísticas sobre a questão ambiental no local, e a realização de entrevistas qualitativas semiestruturadas com pesquisadores do Broa.
Como estratégia de exposição, o artigo está estruturado em cinco seções. Iniciando com esta introdução, passamos à apresentação do ambiente da Represa do Broa e da estrutura de produção de conhecimento científico a seu respeito, na segunda seção. Na terceira seção, discutimos uma primeira situação empírica: os consensos e controvérsias sobre a qualidade ambiental do reservatório, a partir do qual argumentamos sobre a construção social da ideia de degradação ambiental do Broa e sobre a pluralidade dos discursos científicos. Na seção quatro, abordamos o caso da possível contaminação da Represa do Broa no ano de 2014 - nossa segunda situação empírica - para argumentar sobre os efeitos de poder dos discursos científicos, lançando mão das noções de verdade e autoridade. Finalizamos o texto com as conclusões, em que retomamos nossos principais argumentos.

\section{A REPRESA DO BROA E A PRODUÇÃO DE CONHECIMENTO CIENTÍFICO}

A Represa do Broa, no interior do estado de São Paulo, foi construída em 1936 como reservatório da Usina Hidrelétrica Carlos Botelho. Contudo, hoje, ela é utilizada primordialmente de duas outras formas, para além da produção de energia: como praia de água doce para moradores e turistas da região; e como laboratório a céu aberto, sobretudo para os pesquisadores dos Programas de Pós-Graduação em Ecologia e Recursos Naturais (UFSCar) e em Ciências da Engenharia Ambiental (USP).

Segundo Queiroz (2000), a construção de grandes complexos hidrelétricos acabou por suprir em boa medida a necessidade energética de várias regiões do país, de forma que pequenos reservatórios, como a Represa do Broa, deixaram de ter como função principal a geração de energia hidrelétrica. Então, a partir da 
década de 1970, a recreação e o turismo surgiram como alternativas de desenvolvimento para esses espaços, quando se iniciaram os primeiros loteamentos de casas de veraneio no Broa. Esse processo, no entanto, ocorreu de maneira lenta e sem planejamento, com pouca interferência do poder público, esboçando-se também uma forte segregação socioespacial. Esse fenômeno fica evidenciado hoje na distribuição dos diferentes locais no entorno da represa, destacando-se: 1) o Balneário Santo Antônio, um loteamento pertencente ao município de Itirapina, com pequena praia de água doce muito procurada por turistas, oferecendo as atividades de pesca, passeios de barco, churrasco e camping; e 2) a Vila Pinhal, um condomínio fechado de alto padrão junto ao qual localiza-se o Broa Golf Resort, oferecendo serviços de hotelaria, recreação e gastronomia, além de campo de golfe, hípica e aviação.

Por outro lado, a Represa do Broa também se constitui como um importante local de pesquisas nas disciplinas de ecologia, limnologia e engenharia hidráulica e saneamento ${ }^{1}$. Também às margens do reservatório, inclusive, encontra-se o Centro de Recursos Hídricos e Estudos Ambientais $^{2}$ (CRHEA) da USP, um complexo de laboratórios e instalações de campo, em área de 84 hectares. Foi criado em 1976, com o objetivo de fomentar a pesquisa e o desenvolvimento na exploração e proteção dos recursos naturais. Hoje é referência nacional para pesquisas em hidrobiologia, hidráulica, e meteorologia (SHS, s.d.). O CRHEA está vinculado ao Departamento de Hidráulica e Saneamento da Escola de Engenharia

\footnotetext{
${ }^{1}$ O Broa é possivelmente a represa mais estudada no país, sendo objeto de pesquisa de grupos com destacada circulação internacional (IUCIF, 2011; SHS, s.d.; CAMPREGHER, 2016). A proeminência da pesquisa no Broa também foi frequentemente citada pelos cientistas que entrevistamos.

${ }^{2}$ Anteriormente, Centro de Recursos Hídricos e Ecologia Aplicada.
}

de São Carlos e ao Programa de PósGraduação em Ciências da Engenharia Ambiental (este criado em 1989).

Já o Programa de Pós-Graduação em Ecologia e Recursos Naturais (UFSCar), criado em 1976, foi o primeiro curso de pós-graduação na área de ecologia no país (PPG-ERN, s.d.). A despeito da ausência de instalações de campo nas proximidades da represa, esse programa teve participação importante para a consolidação da prática de pesquisa científica no Broa.

Por meio da pesquisa documental de trabalhos científicos ${ }^{3}$ e da realização de entrevistas com pesquisadores, verificamos que as pesquisas no Broa tiveram início na década de 1970. Naquele momento, essas pesquisas foram pensadas como um projeto estratégico e conjunto da USP e UFSCar, que visava responder a três objetivos, quais sejam: 1) o aprofundamento dos estudos de reservatório, posto que, naquele período, não existiam pesquisas sobre ecossistemas lacustres no Brasil (TUNDISI, 1977); 2) o desenvolvimento da abordagem sistêmica e da ecologia, em um contexto internacional de crescente preocupação ambiental, e;3) a capacitação de especialistas e pesquisadores na área da Ecologia e dos recursos hídricos, também como proposta de desenvolvimento institucional das universidades da região.

Assim, por meio do projeto estratégico da USP e UFSCar, envolvendo diferentes objetivos científicos, acadêmicos e institucionais, constituiu-se um aparato de produção de conhecimento científico sobre o Broa. Também, o caráter estratégico do projeto se reflete na formação dos pesquisadores envolvidos, pois torna-se uma estratégia para alunos e jovens pesquisadores participar das pesquisas na Represa do Broa como parte de sua

\footnotetext{
${ }^{3}$ Para esta pesquisa, definiram-se trabalhos científicos como teses de livre docência e de doutoramento, dissertações de mestrado, monografias e trabalhos de conclusão de curso de graduação.
} 
trajetória de formação. Nesse sentido, o projeto possibilitou a formação de uma rede articulada de pesquisadores nas áreas de ecologia, limnologia e engenharia hidráulica, a partir das relações de orientação no meio acadêmico.

O pesquisador 1 - entrevistado por nós - foi e continua sendo uma figura central deste aparato de produção científica: biólogo, livre docente pela USP (1977), fundador dos Programas de Pós-Graduação em Ecologia e Recursos Naturais (UFSCar) e em Ciências da Engenharia Ambiental (USP), e atualmente no Instituto Internacional de Ecologia ${ }^{4}$ (IIE). Ao longo de sua trajetória profissional, o pesquisador 1 foi o principal orientador de trabalhos acadêmicos sobre o Broa, tendo orientado 25 trabalhos entre a década de 1970 e 2014 e, desse modo, participou de forma determinante na formação da rede de pesquisadores da represa. Essa rede, inclusive, ocupa posição dominante no campo científico, principalmente por meio dos grandes financiamentos de pesquisa recebidos por eles, dentre os quais podemos destacar: 1) o Projeto Iniciativa da FAPESP, concedido ao pesquisador 1, em 1978, e através do qual realizou uma tipologia das represas do estado de São Paulo; e 2) a inclusão da Represa do Broa como site do Programa de Pesquisas Ecológicas de Longa Duração ${ }^{5}$ (PELD) do CNPq em 2009.

\footnotetext{
${ }^{4} \mathrm{O}$ Instituto Internacional de Ecologia é uma empresa privada voltada à prestação de serviços na área de gerenciamento de recursos hídricos (IIE, s.d.).

${ }^{5}$ O PELD é uma rede de locais de referência para a pesquisa científica no tema da ecologia de ecossistemas, com a proposta de geração de conhecimento qualificado sobre os ecossistemas nacionais e sua biodiversidade, por meio de longas séries temporais de dados, contando atualmente com 30 sites (CNPq, s.d.). O Programa foi criado pelo próprio pesquisador 1 , quando presidente do CNPq.
}

A partir da operação desse aparato de produção científica, a produção sistemática de discursos sobre o ambiente da Represa do Broa é suportada pelo estatuto da ciência e segue a hierarquia disciplinar do campo científico, com dominância das ciências naturais e engenharias. Também, os discursos sobre o Broa são centrados na realidade física da represa e nas suas possibilidades de gestão, como fica aparente em pesquisas recentes sobre o reservatório e nas falas dos pesquisadores sobre as possibilidades de desenvolvimento econômico da região.

\section{CONSENSOS E CONTROVÉRSIAS SOBRE A QUALIDADE AMBIENTAL DO BROA}

Tendo em vista o contexto de uso e ocupação da Represa do Broa, bem como o aparato de produção de conhecimento científico sobre esse espaço, analisamos duas situações ilustrativas para os propósitos deste estudo. A primeira delas considera a avaliação de pesquisadores do Broa acerca da qualidade ambiental do reservatório e seu entorno. Para isso, realizamos entrevistas qualitativas semiestruturadas com quatro profissionais integrados à rede articulada de pesquisadores e com destacada atuação no local, os quais são apresentados no quadro 1.

De modo geral, existe um consenso entre os pesquisadores a respeito de um processo rápido e preocupante de degradação ambiental na Represa do Broa, apontando para a ocorrência de transformações negativas na dinâmica ecológica do ambiente. 


\begin{tabular}{|c|l|l|}
\hline Entrevistado & \multicolumn{1}{|c|}{ Formação } & \multicolumn{1}{|c|}{ Instituição } \\
\hline Pesquisador 1 & $\begin{array}{l}\text { Doutor em Ciências Biológicas, pelo IB/USP } \\
(1969)\end{array}$ & $\begin{array}{l}\text { Instituto Internacional de } \\
\text { Ecologia }\end{array}$ \\
\hline Pesquisadora 2 & $\begin{array}{l}\text { Doutora em Engenharia Hidráulica e } \\
\text { Saneamento, pela EESC/USP (1988) }\end{array}$ & Docente EESC/USP \\
\hline Pesquisador 3 & $\begin{array}{l}\text { Doutor em Ciências da Engenharia } \\
\text { Ambiental, pela EESC/USP (1994) }\end{array}$ & Docente EESC/USP \\
\hline Pesquisador 4 & $\begin{array}{l}\text { Doutor em Engenharia Hidráulica e } \\
\text { Saneamento, pela EESC/USP (2012) }\end{array}$ & Docente EESC/USP \\
\hline
\end{tabular}

Quadro 1 - Caracterização dos pesquisadores da Represa do Broa entrevistados

Fonte: Informações cedidas nas entrevistas e obtidas por meio de consulta à Plataforma Lattes. Elaborado pelos autores. Observações - Entrevistas realizadas entre os meses de outubro e novembro de 2015.

Contudo nossos entrevistados explicaram esse processo de formas bastante diversas: com diferentes níveis de gravidade e a partir de causas variadas, que contribuiriam mais ou menos na degradação do ambiente a depender da interpretação do cientista. O pesquisador 1, por exemplo, apresenta um diagnóstico ambiental menos preocupante que os demais, afirmando:

Acho que o principal problema de degradação hoje é o volume de pesca que se faz na represa, completamente descuidado. Eu visitei os pescadores lá em cima, na parte de cima da represa. É uma área que era restrita ao acesso, as pessoas quebraram as cercas e entraram, e hoje fazem piquenique. Vão centenas de pescadores. [...] Outra coisa que aconteceu foi que a fauna original foi sendo mudada ao longo do tempo. Isso foi impossível de controlar. Alguém trouxe $\mathrm{Pacu}$, alguém trouxe Tucunaré, alguém trouxe outras espécies que não tinham originalmente. (Pesquisador 1, entrevista concedida em 05/11/2015).

A pesquisadora 2 compartilha das preocupações do pesquisador 1 , mas acrescenta outros fatores ligados também a mudanças climáticas na região. A pesquisadora ainda se mostra mais alarmada pela rapidez com que a degradação ambiental no Broa vem acontecendo.
Pelos resultados que ele ${ }^{6}$ tem me passado, [a represa] deteriorou muito. Muito, muito, muito. Até mesmo em nível das espécies que predominavam e hoje as que predominam, é muito diferente. Eu acredito que naquela época entrava também esgoto, entrava muita coisa na represa. Mas houve um aumento desses esgotos que têm entrado. E eu penso que devido às condições climáticas, que mudaram muito. Essas condições têm levado a uma mudança significativa no comportamento do sistema. [...] O que está chamando a atenção é a rapidez com que isso está ocorrendo. Ou também eles estão jogando muito esgoto, que eu também não sei. Aí também é outro problema, mas as mudanças tem sido muito rápidas. (Pesquisadora 2, entrevista concedida em 05/11/2015).

A pesquisadora 2, portanto, soma as condições climáticas e o lançamento de esgotos no reservatório ao problema da pesca e da introdução de espécies exóticas, levantados pelo pesquisador 1 . O pesquisador 3, por sua vez, apresenta um diagnóstico da qualidade ambiental da represa ainda mais complexo e multicausal. Para ele, os principais problemas a impactarem a qualidade da água no

\footnotetext{
${ }^{6}$ Refere-se ao pesquisador 4, com quem colabora nas pesquisas sobre a Represa do Broa.
} 
Represa do Broa são de origem antrópica e ocorrem tanto na área da bacia hidrográfica, quanto no interior da própria represa. Além das causas já mencionadas pelos outros pesquisadores, ele destaca ainda:

Considerando pelo menos os dados que eu trabalhei, na área de entorno, o que nós temos: nós temos uma mineradora que atua há mais de 40 anos, é um porto de areia. [...] O avanço da cana-de-açúcar é o máximo do problema. $\mathrm{O}$ avanço da cana-de-açúcar e o avanço do eucalipto não é fácil de ser resolvido porque ele é uma fonte não pontual, ele é difuso.
[...] Eu acho que o turismo passa a ser um problema no reservatório, porque não existe uma capacidade, uma infraestrutura para aquilo. [...] Talvez eu diria que outro problema é a falta de gestão, enquanto não houver uma gestão mais próxima do ideal, em que a pessoa tem uma preocupação de reverter aquele quadro, de frear aquele quadro, não vai resolver o problema. (Pesquisador 3, entrevista concedida em 03/11/2015).

Sistematizando todos os fatores de impacto da qualidade ambiental do Broa mencionados pelos pesquisadores em nossas entrevistas, temos:

- Pesca (devido ao lançamento de ceva para atrair os peixes e o uso das iscas).

- Introdução de espécies exóticas (peixes, como o Pacu, o Tucunaré e a Tilápia).

- Condições climáticas (alterações do vento, da temperatura do ar e do regime de chuvas).

- Lançamento de esgotos (tanto o esgoto das casas no entorno do reservatório, como o da cidade de Itirapina que é lançado em um dos tributários da represa).

- Avanço das áreas de agricultura (principalmente o cultivo de cana-de-açúcar, laranja, eucalipto e pinus).

- Mineração (de areia, próxima a um dos tributários da represa).

- Turismo (devido à falta de estrutura física no reservatório).

- Urbanização no entorno da represa (devido à divisão de lotes e à construção de novos condomínios).

- Gestão pública (sendo mencionados conflitos de interesses e falta de comprometimento das prefeituras municipais com a gestão de longo prazo do Broa).

Quadro 2 - Fatores de impacto na qualidade ambiental da Represa do Broa

Fonte: Informações cedidas nas entrevistas. Elaborado pelos autores.

No entanto, como se observa nos excertos das entrevistas apresentados acima, nem todos esses fatores foram mencionados pelos quatro pesquisadores. Tampouco foram apresentados da mesma forma ou com um mesmo nível de preocupação demonstrado por todos. Nesse ponto, é importante considerar que a própria ideia de um processo de degradação ambiental no Broa é uma construção social, no sentido proposto por Hannigan (2009). O autor rompe com a perspectiva realista da temática socioambiental ao afirmar que os problemas ambientais não se constituem enquanto realidades objetivas, associais e evidentes, mas, sim, são construídos pela ação eficaz dos agentes sociais. Os problemas ambientais, portanto, dependem simultaneamente dos fenômenos físicos, químicos e biológicos do ambiente e dos fenômenos sociais de interpretação, argumentação e legitimação das questões ambientais (HANNIGAN, 2009). No caso da Represa do Broa, o ato de nominar aquele conjunto de fenômenos físicos de "degradação 
ambiental" não é óbvio ou natural. Ele apenas se torna possível, aceito ou mesmo naturalizado a partir da ação eficaz dos agentes sociais envolvidos - aqui, os pesquisadores - e da posição privilegiada do conhecimento científico como forma legítima de estudo e tratamento do meio ambiente. Novamente, a possibilidade de classificar a atual situação do reservatório como degradação ambiental está sustentada tanto por fenômenos físicos, como por fenômenos sociais.

A degradação ambiental no Broa, enquanto construção social de um problema ambiental, fica evidenciada pelas divergências e contradições entre as interpretações científicas dos pesquisadores entrevistados. A passagem do simples fenômeno físico para o problema ambiental, que ocorre necessariamente por meio da interpretação, elaboração de discursos e legitimação, é feita de formas distintas por cada pesquisador. Dessa forma, ainda que os profissionais partam da mesma realidade empírica e cheguem ao mesmo denominador, isto é, partam das mesmas transformações na dinâmica ecológica do reservatório e cheguem à mesma ideia de degradação ambiental, cada um deles trilha um caminho diferente para executar essa passagem. Cada um dos diferentes caminhos interpretativos constitui um conjunto de causas possíveis para a degradação do ambiente, hierarquizadas entre si e, principalmente, organizadas na forma de um discurso científico. Assim, podemos afirmar seguramente que o conteúdo da ideia de degradação ambiental no Broa não parte de uma realidade objetiva, evidente e associal. Pelo contrário, a avaliação da qualidade ambiental do reservatório depende igualmente do índice de estado trófico e pH da água, como da posição dos pesquisadores na estrutura do campo científico e dos mecanismos de produção de discursos.

Com isso, também argumentamos que não existe um discurso da ciência sobre o ambiente, ou especificamente sobre a Represa do Broa, no sentido de um discurso unificado e incontestado dentro do próprio campo científico. Há, sim, discursos de cientistas, os quais podem ser múltiplos, heterogêneos e mesmo conflitantes entre si. São discursos assentados na interpretação individual e social do conhecimento científico gerado sobre aquele ambiente, de forma que estão simultaneamente apoiados na realidade física do ecossistema Broa e na realidade social do campo científico e do espaço social como um todo. São discursos que resultam, portanto, da interação do habitus com o espaço social; ou seja, eles expressam uma visão de mundo a partir da relação dinâmica e reflexiva entre as experiências individuais dos agentes sociais e as estruturas objetivas de classificação do mundo social (BOURDIEU, 2008b). Desse modo, deslocamos a ideia de um discurso da ciência para a possibilidade de variados discursos da ciência - com efeito, discursos de cientistas.

\section{CIANOBACTÉRIAS, BALNEABILI- DADE E CONTAMINAÇÃO COMO SINÔNIMOS}

O ocorrido na Represa do Broa, entre outubro e novembro de 2014, permite ainda outras análises sobre a construção social das questões ambientais naquele espaço. Particularmente, esse caso permite discutir a dimensão discursiva dessa construção, com foco para os efeitos de poder dos discursos científicos sobre o ambiente.

As primeiras alterações notadas no Broa, na primeira quinzena de outubro de 2014, foram o aparecimento de peixes mortos nas margens da represa e a constatação visual da coloração esverdeada da água. Naquele momento, o pesquisador 1 e outros cientistas do IIE realizaram testes preliminares da qualidade da água do reservatório e, segundo divulgação da imprensa local, verificaram a presença de cianobactérias possivelmente tóxicas. A 
partir disso, os pesquisadores recomendaram a interdição da Represa do Broa para usos que tivessem contato direto com a água, visando evitar doenças que poderiam ser causadas por tais organismos. Na sequência, a Prefeitura Municipal de Itirapina, responsável pelo Balneário Santo Antônio, fez uma campanha de orientação ao público - através de placas e panfletos informativos distribuídos na entrada do balneário - informando que a represa encontrava-se imprópria para banho. Nesse mesmo período, a Companhia Ambiental do Estado de São Paulo (CETESB) emitiu laudo técnico confirmando a inadequação da qualidade da água aos padrões legais de balneabilidade. No entanto, já no início do mês de novembro, chuvas voltaram atingir a região da Represa do Broa, após um período de estiagem, de forma que a aparência da água do reservatório voltou a suas condições usuais. Com isso, a represa voltou a ser frequentada por banhistas e, finalmente, a Prefeitura de Itirapina divulgou um novo laudo, solicitado por ela a um laboratório de análises ambientais de Rio Claro/SP, informando o retorno da qualidade da água às condições adequadas de balneabilidade.

É interessante notar, porém, que a ciência não produz uma explicação definitiva para essas alterações ambientais no reservatório. Como argumentamos, os discursos científicos são produzidos por cientistas, de formas múltiplas e heterogêneas. Assim, existem variadas explicações para os eventos ocorridos no Broa em 2014. Em nossa entrevista, o pesquisador 1 explica sobre as alterações na represa:

Bom, e o que aconteceu nos últimos dois anos? Como não choveu, diminuiu muito a chuva, e houve uma quantidade grande de pescadores que levaram rações para a represa, a contaminação foi muito grande. Quando não chove, o que acontece: a represa produz energia elétrica, então a empresa que produz energia elétrica tem que fechar a barragem e não deixar a água sair pelo vertedouro para poder aproveitar toda a água. Baixou o nível [da represa], menos $30 \%$ de chuva, a temperatura da água subiu $2^{\circ} \mathrm{C}$ e mais a poluição vinda dos pescadores. Então, juntou mudanças globais com a necessidade de produzir energia elétrica, com os usos múltiplos [da água], especialmente a questão da pesca. Resultado: houve o florescimento de uma alga exótica que está povoando o Brasil inteiro, que é essa Cylindropermopsis. Que causa um problema sério porque ela é tóxica, ela é hepatotóxica, neurotóxica. $\mathrm{E}$ eu tive que pedir para fechar a represa por dois meses, $o$ que causou um prejuízo enorme, porque num fim de semana você tem 10.000 pessoas lá. (Pesquisador 1, entrevista concedida em 05/11/2015).

Nessa explicação, o pesquisador 1 traz a questão dos impactos da pesca e do gerenciamento da produção de energia pela UHE Carlos Botelho, os quais não foram agenciados pela imprensa local nas reportagens que veremos adiante. Outra explicação que obtivemos em entrevista foi a do pesquisador 4, que já executava sua pesquisa sobre cianobactérias na represa nesse período:

Então naquela ocasião, se eu não me engano, foi o índice de coliformes. [...] Os coliformes são indicadores de presença de material fecal, então indica um déficit de saneamento, lançamento de algum tipo de esgoto, etc. São indicadores. E as cianobactérias são justamente esses organismos potencialmente tóxicos que eu falei ${ }^{7}$. [...] Então preventiva-

\footnotetext{
${ }^{7}$ Referência ao estudo que o próprio pesquisador tem realizado sobre cianobactérias em três reservatórios do estado de São Paulo.
} 
mente, na época, eu acho que a balneabilidade do reservatório foi proibida até que as condições melhorassem. Aí, logo depois deu uma chuva, essa chuva contribui para dar uma diluída na coisa, os coliformes e as cianobactérias, e a balneabilidade foi liberada novamente. (Pesquisador 4, entrevista concedida em 13/11/2015).

Contudo, além dessas explicações, a declaração atribuída ao pesquisador 1 veiculada na imprensa local, em 17 de outubro de 2014, articula outro conjunto de fatores para explicar o ocorrido:

Nós estamos acompanhando a Represa do Broa há muito tempo e a situação agora está muito crítica, pois o nível da represa abaixou e a capacidade de retenção da água aumentou muito, como ela tem uma carga de esgotos grande, não havia problema porque chovia e as comportas estavam abertas. Agora com o calor, sem chuvas e com as comportas fechadas, acabou causando o crescimento de algas cianobactéria que pode ser tóxica. Os dados foram encaminhados para um laboratório do Rio de Janeiro para serem estudadas se são ou não tóxicas. [...] Nós estamos recomendando aos prefeitos de Itirapina, Brotas, São Carlos e toda região, para que eles possam impedir os banhistas de manterem o contato com a água do Broa. Esse contato pode provocar problemas de doenças na pele e hepatite, porque além das algas há bactérias e vírus na água. A situação sanitária das águas do Broa é muito grave e perigosa. Tudo isso é um alerta de saúde pública. (CASTRO, 2014b).

O primeiro ponto a se destacar sobre essa fala refere-se ao universo em que o problema se insere: no caso, como problema sanitário, articulando dimensão ambiental e de saúde pública. Nesse contexto, o pesquisador 1 articula a ocorrência de alterações climáticas, que provocaram um período atipicamente seco na região, às necessidades da geração de energia hidrelétrica e à questão sanitária da coleta e tratamento do esgoto. Os dois primeiro fatores, a falta de chuvas e produção de energia, foram mencionados pelo próprio pesquisador em nossa entrevista, realizada cerca de um ano após esses eventos. Entretanto a questão do esgoto não foi; e de forma inversa, a poluição pela ceva e iscas utilizadas por pescadores não aparece nas declarações do pesquisador 1 feitas à imprensa. Podemos supor que essa diferença de argumentação reflete o caráter discursivo do argumento ambiental, tal como defende Hannigan (2009). Isso porque o cientista elabora seu discurso sobre determinada situação ambiental pautado não só nos critérios físicos da situação, mas também levando em consideração quem são seus ouvintes e seus opositores, e qual o contexto sociopolítico que seu argumento se insere - ou seja, levando em consideração seu mercado linguístico, conforme Bourdieu (2008a).

Tal autor compreende o discurso a partir das trocas linguísticas: relações de comunicação entre um emissor e um receptor, fundadas no ciframento e no deciframento (BOURDIEU, 2008a). Essa troca linguística se estabelece face a uma relação de forças determinada, entre um produtor possuidor de um capital linguístico específico e um consumidor que propicia certo lucro material ou simbólico. Os discursos apenas estabelecem seu valor por meio de uma relação com um mercado. Esse mercado linguístico é caracterizado por uma lei especial de formação dos preços, qual seja, o valor do discurso depende da relação de forças que se estabelece entre as competências linguísticas dos locutores. Dito de outro modo, o valor do discurso depende da capacidade dos agentes envolvidos na troca linguística para impor critérios de apreciação mais favoráveis a seus produtos. Essa perspectiva implica que as relações de força linguística não 
são exclusivamente linguísticas, como também a retradução de toda uma estrutura social presente nas interações, através dos modos de falar. Ainda, as trocas linguísticas provocam o efeito de antecipação dos lucros simbólicos do discurso: as condições de recepção antecipadas fazem parte das condições de produção, assim como a antecipação das sanções do mercado contribui para determinar a produção do discurso. Essa antecipação é resultado de um habitus linguístico que tende a funcionar como um sentido daquilo que é aceitável e dos prováveis valores das produções linguísticas em diferentes mercados (BOURDIEU, 2008a).

Assim, retornando ao Broa, talvez o pesquisador 1 tenha considerado que formular o problema da proliferação de cianobactérias na Represa do Broa como uma questão sanitária era uma estratégia discursiva mais eficiente no mercado linguístico em que ele se encontrava, naquele caso lidando tanto com a imprensa local como com os governos municipais. Argumentamos, então, que essa variedade de explicações significa menos uma incerteza da ciência, do que a atuação discursiva, argumentativa e política dos cientistas dentro e fora do campo científico.

Pensando a circulação dos discursos, notamos que as declarações do pesquisador 1 sobre o Broa reverberaram em diversos meios de comunicação de massa locais e mesmo nacionais. Contudo, ao repassar as advertências do pesquisador, os diferentes veículos da imprensa fizeram suas próprias traduções e adequações do conteúdo científico para popularização das informações e facilitação da compreensão aos não especialistas. As preocupações levantadas pelo pesquisador 1 foram noticiadas através de outros termos, como nos exemplos: "Broa está contaminado e pode transmitir graves doenças" (CASTRO, 2014b) ou "Instituto de Ecologia pede interdição da represa do Broa devido à poluição" (PORTAL G1, 18/10/2014).
É interessante notar que, em diversas notícias, a fala do pesquisador 1 é citada, ainda que ele não tenha tratado os problemas de qualidade da água da represa efetivamente por meio das noções de contaminação ou poluição. Quando o faz, o pesquisador trata de um indicativo de contaminação, como na reportagem veiculada pelo Portal G1 (18/10/2014), porém esse indicativo é traduzido como contaminação efetiva ao longo do texto jornalístico. A mudança desses termos, do discurso científico para o jornalístico, pode ser compreendida pela alteração do mercado linguístico em que esse enunciado circula, uma vez que o agente que produz o discurso considera - consciente e inconscientemente - suas condições de recepção nesse mercado, além dos próprios interesses específicos. Nesse caso, o discurso do cientista é diferente do discurso do jornalista porque atende a interesses diferentes, está direcionado a receptores diferentes, circulando em contextos sociais que valorizam distintas lógicas e capitais. Ainda assim, o recurso ao conhecimento científico é tomado como estratégia de legitimação para ambos. $\mathrm{O}$ conhecimento científico, de fato, é utilizado recursivamente pela imprensa, através de discursos que não são propriamente científicos, mas que não deixam de ter na ciência sua base argumentativa.

Ademais, as abordagens para popularização das advertências do pesquisador 1 e sua empresa, assim como a versão original do IIE, podem ser compreendidas como verdades produzidas sobre a Represa do Broa. Como sugere Foucault (2012, 2013), os regimes de verdade são produzidos na relação entre discurso e poder $^{8}$. A verdade não existe sem poder

\footnotetext{
${ }^{8}$ Foucault teoriza o poder como práticas sociais constituídas historicamente. O poder não é algo que se detêm ou que se localize num ponto específico da estrutura social; mas é uma rede de dispositivos ou mecanismos que atinge a todos, do qual não existe exterior. Ele tem caráter relacional - se efetua nas relações de poder - e,
} 
ou fora dele; a verdade é produzida por meio da exclusão e da coerção. O regime de verdade, então, apoia-se sobre um suporte institucional no qual é reforçado e reconduzido por uma variedade de práticas, em particular pela forma com que o saber é aplicado, valorizado e distribuído em uma sociedade. O regime de verdade tem como efeito, também, criar uma aparência de riqueza e fecundidade para a verdade; verdade como força dócil e universal. Entretanto, esse efeito faz ignorar a separação da verdade como intrincado mecanismo de exclusão de todos os discursos que procuram contornar seu regime (FOUCAULT, 2012).

Em síntese, para Foucault (2013), devemos entender por "verdade" um conjunto de procedimentos regulados para a produção, repartição, circulação e funcionamento de enunciados; e a "verdade" - esse conjunto de procedimentos - está circularmente ligada a sistemas de poder que a produzem e a apoiam, e a efeitos de poder que ela induz e que a reproduzem, constituindo um "regime de verdade".

Destarte, as verdades sobre o Broa são produzidas sob certas circunstâncias: 1) São centrada no conhecimento científico - no Broa, pela atuação do IIE e do pesquisador 1, ao levantar o alerta acerca das condições sanitárias da água como foi evidenciado nas notícias analisadas acima, que tomam as falas dos cientistas dessa instituição como fundamento para argumentação no sentido da contaminação das águas do reservatório. Ainda, no que tange à centralidade do conhecimento científico para produção de verdades sobre o Broa, não podemos esquecer todo o aparato de produção científica sobre a localidade, como programa estratégico de desenvolvimento institucional e disciplinar.

mais importante, caráter positivo e produtivo (em oposição as análises que veem o poder exclusivamente como repressão) (MACHADO, 2013; FOUCAULT, 2010).
2) São controladas por instituições políticas - no Broa, forte influência das prefeituras municipais e CETESB, através de comunicados oficiais e solicitações de laudos técnicos. Ambas as prefeituras municipais de Itirapina e São Carlos ${ }^{9}$ emitiram comunicados públicos orientando suas populações para evitar o contato com a água da Represa do Broa; no Balneário Santo Antônio também foram colocadas placas informativas. A CETESB realizou vistoria e considerou a represa imprópria para banho. Além do IIE, esses foram os principais agentes institucionais atuantes no caso da possível contaminação da represa.

3) São amplamente difundidas - no Broa, pelas mídias locais principalmente, como o Jornal Primeira Página (São Carlos, SP), a emissora local EPTV (São Carlos, SP) e websites que, em geral, repercutem as notícias desses veículos. A imprensa ainda é responsável pela popularização do conhecimento científico envolvido, realizando suas próprias traduções e interpretações das falas dos cientistas. Também, os meios de comunicação constituem-se como arena de circulação de discursos e de luta pela classificação da realidade local.

4) São objeto de disputa - no Broa, essa disputa inclui instituições de pesquisa, que têm grande produção científica sobre a represa e, como visto, elaboram um discurso específico sobre o reservatório; inclui os governos municipais e estadual, responsáveis pela gestão do espaço da represa, principalmente nas questões relativas ao saneamento e saúde pública; inclui a imprensa, que se posiciona e produz posicionamentos ao traduzir discursos variados para uma mesma arena de disputa; e enfim, inclui

\footnotetext{
${ }^{9}$ Os moradores de São Carlos, SP são os principais frequentadores da Represa do Broa, que se localiza a $20 \mathrm{~km}$ da cidade. A Prefeitura Municipal de Brotas não se manifestou sobre o caso através da imprensa.
} 
os empreendedores locais e moradores, que têm contato diário com as águas da represa, conhecem-nas a partir de suas experiências práticas e são diretamente afetados tanto pelas mudanças nas condições ambientais do local como pelas mudanças nas classificações dessas condições ambientais.

A produção de verdades sobre a represa e a disputa que se estabelece pela nominação legítima da realidade socioambiental, ficam evidentes na fala de um empreendedor local, quando afirma que "atrapalhou bastante essa história de água contaminada":

Comerciantes reclamam de prejuízos no Broa

Segundo o comerciante Luiz Otávio Geraldo, 50, conhecido como Bigode, o movimento caiu muito desde que a história surgiu. 'Atrapalhou bastante essa história de água contaminada, o movimento caiu $70 \%$, e o fato surgiu bem quando está fazendo calor e nos finais de semana poderia estar lotado', reclamou.

Para Bigode, turistas de outras cidades do Estado de São Paulo ligam para ele pedindo informações sobre a real situação e acabam desistindo de ir até o Balneário, manchando até mesmo a imagem do Broa. 'Pessoas de diversas cidades ligam aqui no meu estabelecimento, quando falamos que a orientação é para não entrar na água, desistem de vir até aqui, muitos são amigos que vêm todo o ano, isso acaba prejudicando a cidade inteira e até mesmo sujando um dos cartões postais da cidade', ressaltou. (CASTRO, 2014a).

Ao tratar o episódio nesses termos, de "história de água contaminada", percebemos que a situação da qualidade da água e a possibilidade de contaminação não é, de forma alguma, um consenso. Pelo contrário, é uma "história", no sentido de ser uma versão possível da realidade local dentre todas aquelas em disputa. Mesmo quando o comerciante informa seus clientes sobre a orientação para que evitem o contato com a água, ele não parece fazê-lo porque acredita na contaminação da represa, mas sim como responsabilidade de reproduzir o discurso oficial dos órgãos públicos.

Mais uma vez, podemos interpretar a situação ambiental do Broa como uma realidade construída socialmente, muito em função da atuação e do sucesso dos agentes sociais envolvidos nesse espaço, os quais disputam o poder de nominação da realidade local. Dessa forma, a existência de problemas ambientais no reservatório depende menos de critérios físicos, fixos e evidentes, do que da dinâmica do mundo social que percebe, interpreta e classifica esses eventos por meio de diferentes lógicas e diferentes visões de mundo. Nesse processo, verdades são produzidas sobre a realidade socioambiental, e estas disputam o poder de classificação legítima.

Aqui, também, argumentamos que a produção de conhecimento científico sobre a Represa do Broa, de forma intensa e estruturada, favorece a constituição de um discurso de autoridade no tratamento das questões ambientais. O conhecimento científico é produzido no interior do campo científico, o qual é fechado e obedece a requisitos de admissão específicos, garantindo a primeira condição do discurso de autoridade - que seja pronunciado pela pessoa autorizada. O campo científico, ademais, possui regras mais ou menos específicas e a illusio garante a adesão dos agentes a essas regras, o que assegura que o discurso científico seja produzido e enunciado em situações legítimas, nas formas discursivas legítimas - outras duas condições do discurso de autoridade (BOURDIEU, 2008a; 2008b). Operando como discurso de autoridade, o conhecimento científico é conhecido e reconhecido como discurso autorizado 
a diagnosticar e solucionar problemas ambientais, impondo-se sobre os demais e fundamentando o senso comum. Nesse sentido, o mesmo comerciante citado acima relata queda de $70 \%$ no número de turistas que frequentam o Broa naquele período do ano, indicando a força desse tipo de discurso na estruturação das práticas. Possivelmente, nem todos dessa parcela de turistas aderem a classificação legítima da realidade socioambiental do reservatório; contudo, tampouco parecem contestá-lo.

Existe, porém, outra parcela de turistas e moradores que se opõem ao discurso científico dominante, tanto por meio de suas falas, como de suas práticas. Menos de um mês após as primeiras declarações do pesquisador 1 , chuvas voltaram a atingir a região do Broa, fazendo com que a água do reservatório voltasse praticamente a sua coloração normal. Esses agentes, então, voltaram a frequentar a represa a despeito da manutenção das orientações da CETESB e prefeituras para que se evitasse o contato com a água. Alguns desses usuários afirmaram (JORNAL PRIMEIRA PÁGINA, 11/11/2014; PORTAL G1, 12/11/2014) :

A água está limpinha. Eu vi a placa, mas vim de Rio Claro aqui e vou nadar. Não vai acontecer nada. [...] Não cheirava esgoto e nem parecia estar estragada.

Não sou daqui, mas vi na televisão que a água está contaminada, acho que é mentira porque está todo mundo nadando.

Não acredito de jeito nenhum, nunca teve problema aqui. Isso aqui tá tudo bem. Vou continuar vindo aqui com certeza.

Nesses casos, o discurso dos órgãos governamentais, assim como o discurso veiculado pela imprensa - cuja argumentação, em ambos, tem como base o conhecimento científico -, não efetuam seu poder de autoridade sobre esse público, que o contesta a partir do senso comum, da experiência cotidiana na represa e das práticas sociais.

Ainda, os meios de comunicação que noticiaram o uso do Broa pelos banhistas, o fizeram em tom de denúncia:

Apesar das orientações para que
visitantes não entrem na represa
do Broa por causa da contami-
nação da água, muitos turistas
aproveitaram o final de semana
de calor para se divertir e desres-
peitar a solicitação da Cetesb e do
Instituto Internacional de Ecolo-
gia, uma vez que a água conta-
minada pode transmitir diversas
doenças, entre elas hepatite.
(JORNAL PRIMEIRA PÁGINA,
11/11/2014).

[...] O Primeira Página denunciou ontem que os turistas estavam nadando normalmente nas águas da represa mesmo com a informação da Cetesb que há risco de contaminação. (JORNAL PRIMEIRA PÁGINA, 12/11/2014).

Esse caráter acusatório das notícias se apoia na legitimação do discurso de autoridade da ciência, tanto aquele produzido pelo pesquisador 1 e pelo grupo de cientistas ligados a ele, quanto por organismos governamentais de regulação ambiental, como a CETESB. Ainda que a imprensa faça a tradução do conteúdo desse discurso de autoridade sem a sistematicidade característica do método científico, reiteramos que sua argumentação é baseada nessa forma de conhecimento.

Do mesmo modo, quando a Prefeitura Municipal de Itirapina buscava argumentos legítimos para liberar oficialmente o uso da represa, recorreu a outro laboratório de análises ambientais para realização de laudo técnico. $\mathrm{O}$ novo laudo, elaborado pelo Laboratório São Lucas, de Rio Claro, SP, que não tem ligações com a rede de pesquisadores articulada pelo pesquisador 1 , atestou a qualidade adequada das águas do reser- 
vatório no final de novembro de 2014. O caso da "contaminação" da Represa do Broa se encerrou assim, fundamentado em novos argumentos de autoridade do discurso científico, os quais se somam ao diagnóstico dos turistas e moradores para a produção de uma nova verdade sobre a situação ambiental da represa.

\section{CONCLUSÃO}

A construção da moderna questão ambiental, bem como sua relação íntima com a produção de conhecimento científico sobre o meio ambiente, pode ser analisada nas mais diferentes escalas. Neste artigo, procuramos discutir tal construção a partir do estudo de um pequeno reservatório no interior do estado de São Paulo, que - no entanto - possui um grande e importante aparato de produção científica a seu respeito. A operação dessa estrutura científica resulta na produção de discursos sobre o ambiente do Broa, amplamente suportados pelo estatuto da ciência e submetidos à hierarquia disciplinar do campo científico.

Contudo a produção discursiva sobre a Represa do Broa não é homogênea, nem mesmo quando analisada dentro da categoria dos discursos científicos. Não há um discurso da ciência, em sentido consensual ou incontestado; pelo contrário, há variados discursos da ciência. A rigor, existe apenas discursos de cientistas, que podem ser múltiplos, heterogêneos e mesmo conflitantes entre si. Assim, são discursos que dependem da relação dinâmica e reflexiva entre a interpretação individual, as estruturas sociais de classificação do mundo e a realidade física do ambiente. Como apresentado, a avalição da qualidade ambiental do Broa demonstra como um ambiente pode ser interpretado de modo bastante diverso, mesmo por cientistas inseridos no mesmo aparato de produção científica.

As controvérsias sobre a qualidade ambiental do Broa também evidenciam o processo de construção social do ambiente. A degradação ambiental, antes de uma realidade objetiva, é o processo de interpretação, nominação, e legitimação de certos fenômenos físicos daquele ambiente. Nesse sentido, a passagem do simples fenômeno físico para o problema ambiental depende da ação dos agentes sociais, a qual pode ser realizada por diferentes caminhos interpretativos e discursivos.

Ainda, o caso da possível contaminação das águas, enquanto episódio de disputa pela nominação das condições ambientais da Represa do Broa, ilustra nosso argumento acerca da dimensão discursiva da problemática ambiental. Como visto, os discursos hegemônicos trazem uma argumentação embasada no conhecimento científico produzido sobre a represa, ainda que façam, por vezes, suas próprias traduções e interpretações desse conhecimento. Contudo existem também outras falas em circulação nesse espaço social, com posicionamentos divergentes, que podem ou não utilizar-se do conhecimento científico. Esses outros discursos utilizam-se, ainda, da argumentação fundada no conhecimento prático, na experiência cotidiana, no senso comum e nas práticas sociais. Nesse universo de disputas, são produzidas verdades sobre a realidade do reservatório para explicar e estruturar o espaço. Tais verdades podem, também buscar elementos de um discurso de autoridade que favoreça sua legitimação na disputa classificatória.

Em síntese, o caso da possível contaminação do Broa revela que a autoridade da ciência, como entidade designada para o tratamento dos problemas ambientais, é variável de acordo com os interesses dos grupos que disputam a classificação da realidade socioambiental. Diferentes grupos envolvidos em determinada contenda ambiental, podem selecionar quais argumentos científicos serão ouvidos, utilizados e reproduzidos; e quais argumentos científicos, ao contrário, serão 
desconsiderados. Nesse sentido, não há relação automática entre a produção de conhecimento científico e autoridade da ciência, uma vez que tal conhecimento só opera como discurso de autoridade nas circunstâncias adequadas de alinhamento com os interesses dos grupos sociais locais. Novamente, não há uma fala da ciência, mas sim falas de cientistas: múltiplas, heterogêneas e conflitantes. Dependendo do contexto da disputa classificatória sobre o meio ambiente, esses cientistas poderão ter suas falas e sua autoridade individualmente requisitadas, no sentido de legitimar uma ou outra verdade socioambiental.

\section{REFERÊNCIAS}

ALMEIDA, Jalcione; PREMEBIDA, Adriano. Histórico, relevância e exploração ontológicas da questão ambiental. Sociologias, Porto Alegre, ano 16, n. 35, p. 14-33, jan./abr. 2014.

CAMPREGHER, Raiza. Um ambiente, tantas verdades: estudo sociológico dos discursos científicos sobre a Represa do Lobo/Broa. 2016. 153f. Dissertação (Mestrado em Sociologia) - Centro de Educação e Ciências Humanas, Universidade Federal de São Carlos, São Carlos, SP, 2016.

BOURDIEU, Pierre. Economia das trocas linguísticas: o que falar quer dizer. São Paulo: EdUSP, 2008a.

Para uma sociologia da ciência. Lisboa: Edições 70, 2008b.

CASTRO, Lucas. Comerciantes reclamam de prejuízos no Broa. Jornal Primeira Página, São Carlos, 18 nov. 2014a.

Broa está contaminado e pode transmitir graves doenças. Jornal Primeira Página, São Carlos, 17 out. 2014b.

CONSELHO NACIONAL DE DESENVOLVIMENTO CIENTÍFICO E TECNOLÓGICO (CNPq). Programa de Pesquisas Ecológicas de Longa Duração (PELD), [s.d.]. Disponível em: <http://www.cnpq.br/web/guest/apresentacao7>. Acesso em: 24 dez. 2015.

DEPARTAMENTO DE HIDRÁULICA E SANEAMENTO (SHS). EESC-USP. Represa do
Broa. [s.d.]. Disponível em: <http://www1. eesc.usp.br/shs/index.php/represa-dolobo>. Acesso em: 9 set. 2013.

. Departamento de Hidráulicae Saneamento. [s.d.]. Disponível em: <http:/ / www.shs.eesc. usp.br/administracao/historico/>. Acesso em: 12 maio 2015.

FOUCAULT, Michel. Em defesa da sociedade: curso no Collège de France (1975-1976). São Paulo: WMF Martins Fontes, 2010.

A ordem do discurso: aula inaugural no Collège de France, pronunciada em 2 de dezembro de 1970. São Paulo: Edições Loyola, 2012.

2013.

. Microfísica do poder. São Paulo: Graal,

PORTAL G1. Instituto de Ecologia pede interdição da represa do Broa devido à poluição. São Carlos e Araraquara, 18 out. 2014.

. Mesmo com água imprópria, represa do Broa ainda é usada por banhistas. São Carlos e Araraquara, 12 nov. 2014.

HANNIGAN, John. Sociologia ambiental. Petrópolis: Vozes, 2009.

INSTITUTO INTERNACIONAL DE ECOLOGIA (IIE). Quem somos. [s.d.]. Disponível em: <http://www.iie.com.br/ index.php/sobre/quem-somos>. Acesso em: 23 maio 2015.

IUCIF, Nicolau Gentil. Estudos na Represa do Lobo (Itirapina/Brotas-SP): revisão de algumas teses e dissertações produzidas pelo PPGSEA. 2011. 48f. Monografia (Graduação em Engenharia Ambiental) - Departamento de Hidráulica e Saneamento, Universidade de São Paulo, São Carlos, SP, 2011.

JORNAL PRIMEIRA PÁGINA. Redação. Frequentadores do Broa desrespeitam orientações e entram na água contaminada. São Carlos, 11 nov. 2014.

Redação. Cetesb confirma que água do Broa é imprópria para banho. São Carlos, 12 nov. 2014.

MACHADO, Roberto. Por uma genealogia do poder. Introdução. In: FOUCAULT, Michel. Microfísica do poder. São Paulo: Graal, 2013. p. 7-34. 
PROGRAMA DE PÓS-GRADUAÇÃO EM ECOLOGIA E RECURSOS NATURAIS/ UFSCar (PPG-ERN). História da criação e funcionamento do programa, [s.d.]. Disponível em: <http://www.ppgern.ufscar.br/ apresentacao>. Acesso em: 12 maio 2015.

QUEIROZ, Odaléia Telles Marcondes Machado. Impactos das atividades turísticas em área de reservatório: uma avaliação sócioambiental do uso e ocupação na área da Represa do Lobo, município de Itirapina, SP. 2000. 238f. Tese (Doutorado em Ciências da Engenharia Ambiental) - Escola de Engenharia de São Carlos, Universidade de São Paulo, São Carlos, SP, 2000.

TUNDISI, José Galizia. Produção primária, "standing stock", fracionamento do fitoplancton e fatores ecológicos em ecossistema lacustre artificial (Represa do Broa, São Carlos). 1977. 409f. Tese (Livre docência) - Faculdade de Filosofia, Ciências e Letras de Ribeirão Preto, Universidade de São Paulo, Ribeirão Preto, SP, 1977.

\section{Sobre os autores:}

Raiza Campregher: Bacharela em Ciências Sociais e mestra em Sociologia pela Universidade Federal de São Carlos (UFSCar). Doutoranda no Programa de PósGraduação em Sociologia da UFSCar. E-mail: raiza.campregher@gmail.com

Rodrigo Constante Martins: Bacharel e mestre em Ciências Sociais pela Universidade Federal de São Carlos (UFSCar). Doutor em Ciências da Engenharia Ambiental (interdisciplinar), na área de sociologia ambiental, pela Universidade de São Paulo. Pós-doutorado em Sociologia pela École des Hautes Études em Sciences Sociales de Paris. Professor do Departamento de Sociologia e do Programa de Pós-Graduação em Sociologia da UFSCar. E-mail: constantemartins@gmail.com 